J. Lake Sci. (湖泊科学), 2013, 25(3):352-358

http: //www. jlakes.org. E-mail: jlakes@niglas.ac.cn

(C) 2013 by Journal of Lake Sciences

\title{
复合型前置库系统去除面源主要污染物的研究”
}

\author{
边 博 $^{1}$, 吴海锁 ${ }^{1}$, 徐志荣 ${ }^{2}$, 王惠中 ${ }^{1}$, 姜伟立 ${ }^{1}$ \\ ( 1 : 江苏省环境科学研究院,南京 210036) \\ ( 2 :河海大学环境学院,南京 210098$)$
}

\begin{abstract}
摘 要: 以江苏省溧阳市塘马水库水源地水质安全保障工程为背景, 针对水库型水源地面源污染存在的主要问题,构建 以沉淀区、浅水区、深水区、潜流人工湿地及生物填料组成强化净化区的复合型前置库分区净化系统, 研究面源主要污染 物去除规律, 为工程示范提供技术参数. 结果表明, 系统滞水时间为 $1 \mathrm{~d}$ 时, 去除氮、磷、 $\mathrm{COD}_{\mathrm{Cr}}$ 均有良好效果, 分别达到了 $67.2 \% 、 68.2 \%$ 及 $89.3 \%$, 滞水时间为 $2 \sim 3 \mathrm{~d}$ 时各污染物去除率增加较少并趋于稳定. 引人潜流湿地及强化净化区明显 提高了 SS、氮、磷、有机物的去除效果, 特别是提升了对小颗粒 (粒径小于 $15 \mu \mathrm{m}$ ) 的去除效果, 基于上述研究结果, 建议工 程示范中滞水时间为 $2 \sim 3 \mathrm{~d}$,并适当优化系统分区结构,提高复合型前置库的净化效率及面积利用率.
\end{abstract}

关键词: 面源污染;复合型前置库系统;功能区;营养盐;悬浮颗粒物;塘马水库

\section{Eliminating non-point source pollution in a pre-dam complex system in the Tangma Res- ervoir, Jiangsu Province}

\author{
BIAN Bo ${ }^{1}$, WU Haisuo ${ }^{1}$, XU Zhirong ${ }^{2}$, WANG Huizhong ${ }^{1} \& J_{\text {JANG Weili }}^{1}$ \\ (1: Jiangsu Provincial Academy of Environmental Science, Nanjing 210036, P. R. China) \\ (2: College of Environment, Hohai University, Nanjing 210098, P. R. China)
}

Abstract: In this study, the efficiencies of a pre-dam complex system for non-point source pollution control was investigated for the management of the Tangma Reservoir in Liyang City, Jiangsu Province. The pre-dam complex is composed of settling area ( A), shallow-water area (B), deep-water area 1 (C), deep-water area 2 (D), surface flow wetland (E), and biological membrane purification area (F). The results showed that the pre-dam complex system under the study contributed to significant improvement in the quality of agricultural non-point source pollution flowing through the pre-dam. The removal of TN, TP, COD $\mathrm{Cr}$ could be up to $67.2 \%, 68.2 \%$ and $89.3 \%$, respectively, when the retention time was $1 \mathrm{~d}$. The removal efficiency was increased with increasing of retention time, while the increment was small and stable. Moreover, increased areas ( E and F) could significantly improve the removals of $\mathrm{SS}, \mathrm{TN}, \mathrm{TP}$ and $\mathrm{COD}_{\mathrm{Cr}}$, particularly the smaller SS which was consisted of size less than $15 \mu \mathrm{m}$. Furthermore, based on laboratory results, it was suggested that the retention time be $2-3 \mathrm{~d}$ in the Tangma project, and the system be optimized to improve the purification efficiency and high utilization of the area.

Keywords: Non-point sources pollution; pre-dam complex system; functional areas; nutrients; SS; Tangma Reservoir

随着我国对饮用水水源地保护的日益重视,水源地周边的点源污染得到了有效的遏制. 面源污染的影 响比例和危害越来越突出, 特别是以水库型水源地为主的中小城镇, 其周边的农村生活污水、稻田排水等农 业面源污染通过降雨或地表径流的方式对水源地水质造成严重的危害 ${ }^{[1-2]}$. 该类污染的特点主要体现在初 期来水污染物浓度高、负荷大, 需要净化处理; 而后期来水水量较大, 污染程度低可直接排放进人水源地. 对 于这类污染的控制常通过过程削减技术来降低人库进水的污染程度, 其中较为常用的是前置库技术, 通过 在水源地水库前设置前置库 (或滞留塘) 对初期来水进行截留、沉降、吸附、降解等方式净化水质后排人水源 地水库 ${ }^{[3]}$.

* 江苏省科技支撑计划项目 (BE2011809) 和江苏省自然科学基金项目 (BK2010091) 联合资助. 2012-06-06 收稿; 2012-09-24 收修改稿. 边博,男,1978 年生,博士, 高级工程师;E-mail:bianbo1@ 163. com. 
目前对于前置库并无明确、统一的定义, 一般认为利用水库存在的从上游到下游的水质浓度变化 梯度特点, 将水库分为一个或若干个子库与主库相连, 通过对前置子库中污染物的净化, 实现以低污 染水质溢流人库, 以保证或改善主库水源的水质. 对于前置库研究可追溯到 $1950 \mathrm{~s}$ 后期, 国外一些学者 如德国的 Uhlmann ${ }^{[4]}$ 、丹麦的 Nyholm ${ }^{[5]}$ 、前捷克的 Fiala ${ }^{[6]}$ 等将其应用于水库的富营养化治理及流域面 源污染控制, 并提出了一系列前置库的设计参数及氮、磷等营养盐净化机理. 在我国的研究虽然起步 较晚, 但已应用于滇池 ${ }^{[7-8]}$ 、太湖 ${ }^{[9-10]}$ 等流域的面源污染控制, 水库富营养化防治 ${ }^{[11-12]}$, 河道水环境治 理 $^{[13]}$ 等方面.

早期的前置库主要通过调节来水的滞水时间, 达到沉降污染物及泥沙的作用, 并未涉及到根据来水的 特点以及水生植物、水生动物等生态修复技术的使用条件. 因地制宜地构建前置库分区净化系统, 便于提高 对来水中氮、磷等营养盐的去除效果. 近年来随着农业面源污染的加剧, 水源地来水中氮、磷含量显著增加, 使得传统的前置库系统在氮、磷净化效果上凸显不足, 尤其表现在冬季低温条件 ${ }^{[14-15]}$, 如段伟等 ${ }^{[11]}$ 研究发现 冬季铵态氮 $\left(\mathrm{NH}_{4}^{+}-\mathrm{N}\right)$ 、总氮 $(\mathrm{TN})$ 的去除速率远低于夏季, 仅为夏季的 $1 / 4$ 左右. 为此, 国内外学者提出采用 透水坝、生物强化等工程技术与传统前置库系统进行组合 ${ }^{[11,14,16-17]}$, 充分发挥物理拦截吸附及生物净化作 用,提升前置库对氮、磷等营养盐净化效果.

因此, 本文结合溧阳市塘马水库水质安全保障工程背景及来水中污染物特征, 从技术集成角度出发, 引 人潜流人工湿地和由生物载体填料构建的强化净化分区, 改进了传统的前置库系统, 因地制宜地构建了复 合型前置库分区净化系统, 并在实验室尺度下探讨复合型前置库系统及各功能区对面源污染中 $\mathrm{SS} 、$ 氮、磷等 净化效果及规律, 确定了复合型前置库去处污染物最优的工况参数, 为前置库净化系统在溧阳市塘马水库 水质安全保障工程中的应用提供科学依据.

\section{1 试验材料与方法}

\section{1 复合型前置库系统室内模型的建立}

复合型前置库系统由 6 个功能区构成, 分别是沉淀区 $(A)$ 、浅水区 $(B) 、$ 深水区 $(C)$ 和 $(D)$ 、潜流人工湿 地 $(\mathrm{E}) 、$ 强化净化区 $(\mathrm{F})$, 其工艺流程如图 1a 所示, 其中前 4 个功能区 ( A, B, C, D ) 构成传统型前置库系统. 考虑到传统型前置库对氮、磷的净化作用不足, 引人潜流人工湿地 $(\mathrm{E})$, 进一步强化营养盐物质的去除. 在经 过人工湿地处理后, 预计水中氮、磷浓度降低到一定程度, 可能属于低氮、磷条件, 引人强化净化区的目的是 强化对低氮、磷时的水质净化. 复合型前置库的室内模型采用有机玻璃自制, 其示意图及相关设计参数如图 $1 \mathrm{~b}$ 所示. 其中, 除 B 区深度为 $0.20 \mathrm{~m}$ 外, 其它功能区深度均为 $0.30 \mathrm{~m}$.

另外, 考虑到在冬季 (12 月初 -1 月中旬) 开展试验, 因此在 B 区、 C 和 D 区、E 区分别种植较耐寒植物 菖蒲、伊乐藻及芦苇, 其中, B 区植物为菖蒲, C 和 D 区为伊乐藻, E 区为芦苇, 其相应的种植密度分别为 50 株 $/ \mathrm{m}^{2} 、$ 25 丛 $/ \mathrm{m}^{2}$ 、36 丛 $/ \mathrm{m}^{2}$ 及 55 株 $/ \mathrm{m}^{2}$. 而在有生物载体填料构成的 $\mathrm{F}$ 区则水面铺满多孔圆柱型填料 $(\mathrm{d} \times \mathrm{h}: 15 \mathrm{~mm} \times$ $5 \mathrm{~mm}$, 并设 19 个多孔), 铺设厚度约为 $40 \mathrm{~mm}$, 并通过潜水洜曝气, 强度约为 $1.8 \mathrm{~L} / \mathrm{min}$.

\section{2 试验水质及分析}

根据江苏省溧阳市塘马水库来水水质 $\left(\mathrm{TN}: 2 \sim 8 \mathrm{mg} / \mathrm{L} ; \mathrm{NH}_{4}^{+}-\mathrm{N}: 0.8 \sim 3.0 \mathrm{mg} / \mathrm{L} ; \mathrm{SS}: 20 \sim 50 \mathrm{mg} / \mathrm{L}\right.$; TP: $\left.0.8 \sim 2.8 \mathrm{mg} / \mathrm{L} ; \mathrm{COD}_{\mathrm{Cr}}: 20 \sim 90 \mathrm{mg} / \mathrm{L}\right)$, 相应地配置一定浓度的室内模拟废水, 放于内置摚拌装置的 $140 \mathrm{~L}$ 供 水桶内, 并设置搅拌转速为 45 转/ $\mathrm{min}$, 以防止模拟废水浓度不均一及 $\mathrm{SS}$ 沉降. 供水桶内的潜水洜以 $0.28 \mathrm{~m}^{3} / \mathrm{d}$ 的供水流速向前置库室内模型供水. 另外, 模拟废水中 SS 采用江苏某湖底泥配置, 底泥含水率和 有机质含量分别为 $39.28 \%$ 和 $2.72 \%, d(10) 、 d(50) 、 d(90)$ 分别为 $2.236 、 15.042$ 和 $53.091 \mu \mathrm{m}$; 而氮、磷等 营养盐则通过硝酸钠、氯化铵、磷酸二氢钾和葡萄糖分析纯试剂进行配置, 控制进水浓度为现场最高来水浓 度的 1.5 倍且基本不含有机氮、磷, 同时试验过程中也模拟了不同浓度配水间歇条件下连续运行对污染物 去除率基本稳定时, 分析系统对污染物的去除规律.

试验通过为期 1 个月的连续运行直到 $\mathrm{F}$ 区生物膜生长, 按照不同浓度配水条件, 当系统出水水质基本稳 定后, 分阶段对室内配置的模拟废水进行处理,每隔 $12 \mathrm{~h}$ 或 $24 \mathrm{~h}$ 采集各功能区出水水样, 根据《水和废水监测 
分析方法 (第四版) 》 ${ }^{[18]}$ 分别测定 $\mathrm{SS} 、 \mathrm{TN} 、 \mathrm{NH}_{4}^{+}-\mathrm{N} 、 \mathrm{COD}_{\mathrm{Cr}} 、 \mathrm{TP} 、 \mathrm{TDP}$ 指标. 其中 $\mathrm{NH}_{4}^{+}-\mathrm{N} 、 \mathrm{NO}_{3}^{-}-\mathrm{N} 、 \mathrm{TDP}$ 为过 $0.45 \mu \mathrm{m}$ 醋酸纤维滤膜后测定. 水样中颗粒粒径采用激光光透式粒度仪 (Mastersize 2000, Malvern Instruments Ltd, UK) 测定.

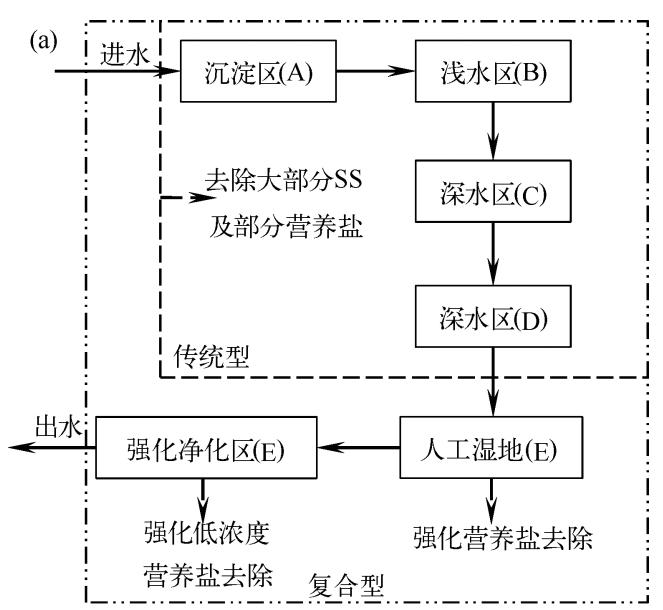

水流方向 $\longrightarrow$ 功能作用

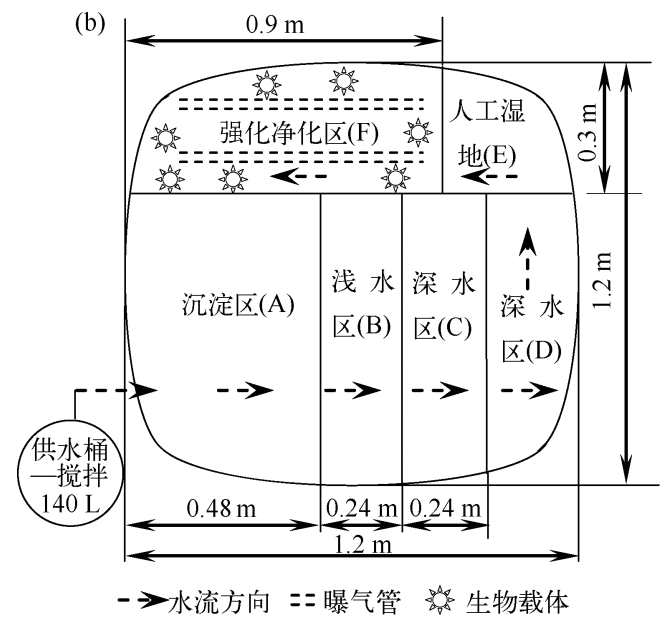

图 1 复合型前置库系统工艺流程 $(\mathrm{a})$ 及结构 $(\mathrm{b})$

Fig. 1 Process flow (a) and schematic diagram (b) of an integrated pre-dam

\section{3 表征指标与计算}

为了更有效地表征复合型前置库系统的净化效率, 分别设定了总体去除率 $(\eta)$ 、各功能区单独去除率 $(\delta)$ 、各功能区累积去除率 $(\varphi)$ 、各功能区对污染物去除贡献率 $(\lambda)$ 及单位面积去除贡献率 $(\varepsilon)$, 计算公 式为:

$$
\begin{gathered}
\eta=\left(C_{\text {out }}\right)_{\mathrm{F}} / C_{\text {in }} \times 100 \% \\
\delta=\left(C_{\text {out }}\right)_{i} /\left(C_{\text {in }}\right)_{i} \times 100 \% \\
\varphi=\left(C_{\text {out }}\right)_{i} / C_{\text {in }} \times 100 \% \\
\lambda=Q_{i} / \sum Q_{i} \times 100 \% \\
\varepsilon=\lambda_{i} / A_{i}
\end{gathered}
$$

式中, $\left(C_{\text {out }}\right)_{\mathrm{F}}$ 为 $\mathrm{F}$ 区出水浓度 $(\mathrm{mg} / \mathrm{L}) ; C_{\mathrm{in}}$ 为进水浓度 $(\mathrm{mg} / \mathrm{L}) ;\left(C_{\text {out }}\right)_{i}$ 为某功能区的出水浓度 $(\mathrm{mg} / \mathrm{L})$; $\left(C_{\mathrm{in}}\right)_{i}$ 为某功能区的进水浓度 $(\mathrm{mg} / \mathrm{L}) ; i$ 为某个功能区; $A_{i}$ 为某功能区的面积 $\left(\mathrm{m}^{2}\right) ; Q_{i}$ 为某功能区的去除 量 $(\mathrm{mg}) ; \sum Q_{i}$ 为总的去除量 $(\mathrm{mg})$.

\section{2 结果}

\section{1 室内复合型前置库系统对 SS 的净化效果}

复合型前置库系统中 SS 总体去除率随滞水时间的增加而增加, 且在滞水 $12 \mathrm{~h}$ 后, SS 去除率可高达 $80 \%$ 以上,在滞水 $48 \mathrm{~h}$ 后能达 $90 \%$ 左右,这表明复合型前置库系统对 SS 起到良好的净化效果, 但同时也反 映出长时间滞水 $(>48 \mathrm{~h})$ 并未能大幅提高 SS 总体去除率. 其次, 各功能区对 SS 的累积去除率与总体去除率 呈现相同的规律, 随滞水时间的增加而增加, 且增幅在滞水时间大于 $48 \mathrm{~h}$ 后减缓. 最后, 对比传统型前置库 ( D 区累积去除率) 及复合型前置库 ( F 区累积去除率) 可以明显发现,在滞水前 $36 \mathrm{~h}$ 内引人 $\mathrm{E}$ 区和 $\mathrm{F}$ 区后的 复合型前置库能有效地提高 $\mathrm{SS}$ 的总体去除率,平均提高了 $8.51 \%$; 而滞水后的 $36 \mathrm{~h}$ 也能平均提高 $3 \%$ 左右 (图 2a). 
A 区在 SS 去除过程中呈现主要作用, 其贡献率高达 $66.8 \%$; 其次是 B 区和 E 区, 各自贡献率均高于 $10 \%$, 且 B 区略高于 E 区, 而 F 区最低, 仅为 $1.48 \%$ 。而相对区单位面积贡献率而言, A 区最高, 而 $\mathrm{E}$ 区明显 高于 B 区, 约是 B 区的 2 倍, 体现出其高效的单位贡献率. 而对于各功能区的单独去除率亦呈现与单位面积 贡献率相似的规律, A 区最高, E 区明显高于 B 区 (图 $2 b$ ). 另外, 图 $2 \mathrm{~b}$ 更为明确地反映出传统型前置库与复 合型前置库之间的差异,引人 $\mathrm{E}$ 区和 $\mathrm{F}$ 区后, 其对 $\mathrm{SS}$ 去除的贡献率可提高 $12.5 \%$, 且主要作用为 $\mathrm{E}$ 区.
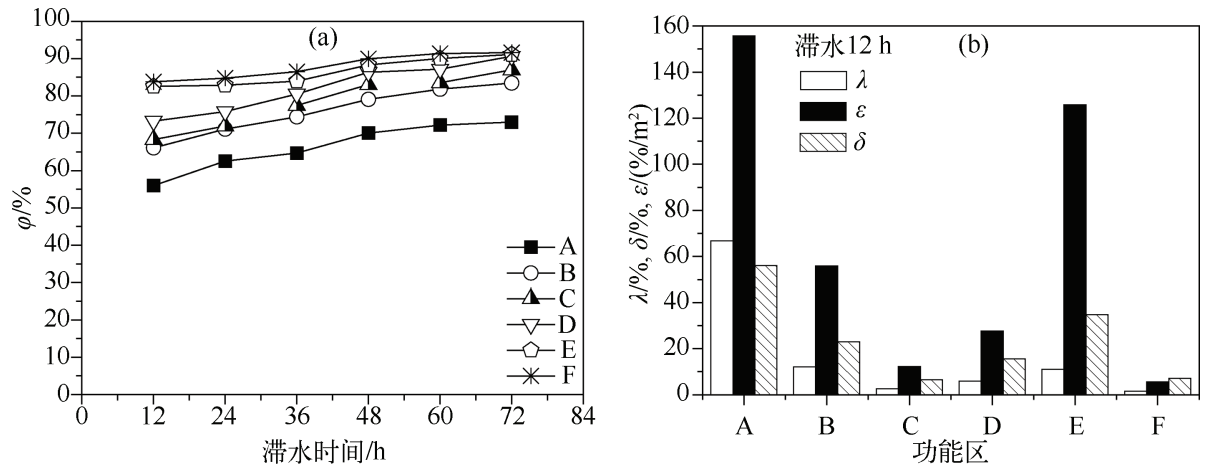

图 2 不同滞水时间下各功能区对 SS 的累积净化效果 (a) 及滞水 $12 \mathrm{~h}$ 后各功能区的贡献率、 单位面积贡献率及单独去除率 $(b)$

Fig. 2 The influence of retention time on SS removal in pre-dam (a) and contribution rate with retention time of $12 \mathrm{~h}(\mathrm{~b})$ for different functional areas

从系统整体出水粒径来看, 经过 $72 \mathrm{~h}$ 处理后, 出水的 $\mathrm{SS}$ 粒径明显减小且主要集中在 $5 \sim 40 \mu \mathrm{m}$, 可占出 水 SS 的 $90.2 \%$. 相比进水 SS 粒径而言, 粒径大于 $40 \mu \mathrm{m}$ 的颗粒在前置库中能完全被去除, 粒径小于 $5 \mu \mathrm{m}$ 的颗粒含量也明显减少 (图 3a). 不同功能区对粒径去除之间存在差异, 在滞水时间为 $12 \mathrm{~h}$ 时, A 区出水中大 颗粒( > $100 \mu \mathrm{m}$ ) 完全被去除,而粒径在 30 100 $\mu \mathrm{m}$ 之间的颗粒大部分被去除, $5 \sim 30 \mu \mathrm{m}$ 之间的颗粒部分被去 除, 而 $<5 \mu \mathrm{m}$ 完全未被沉降. 而经过 B、C、D 区后, 粒径大于 $40 \mu \mathrm{m}$ 颗粒完全被去除, $5 \sim 40 \mu \mathrm{m}$ 颗粒含量明 显增加, 意味着颗粒粒径小于 $5 \mu \mathrm{m}$ 部分被截留; 而经过 $\mathrm{E}$ 和 $\mathrm{F}$ 区后, 出水粒径中 $5 \sim 40 \mu \mathrm{m}$ 颗粒含量进一步 提高; 而 $<5 \mu \mathrm{m}$ 颗粒含量进一步降低,表明颗粒粒径 $<40 \mu \mathrm{m}$ 部分被进一步截留. 此外,在滞水时间的作用 下, 又促使了该部分粒径的沉降, 使得出水粒径以 $5 \sim 40 \mu \mathrm{m}$ 为主. 当然, 相比传统型前置库, 复合型前置库 能够有效地提高 $40 \mu \mathrm{m}$ 以下颗粒的去除率.
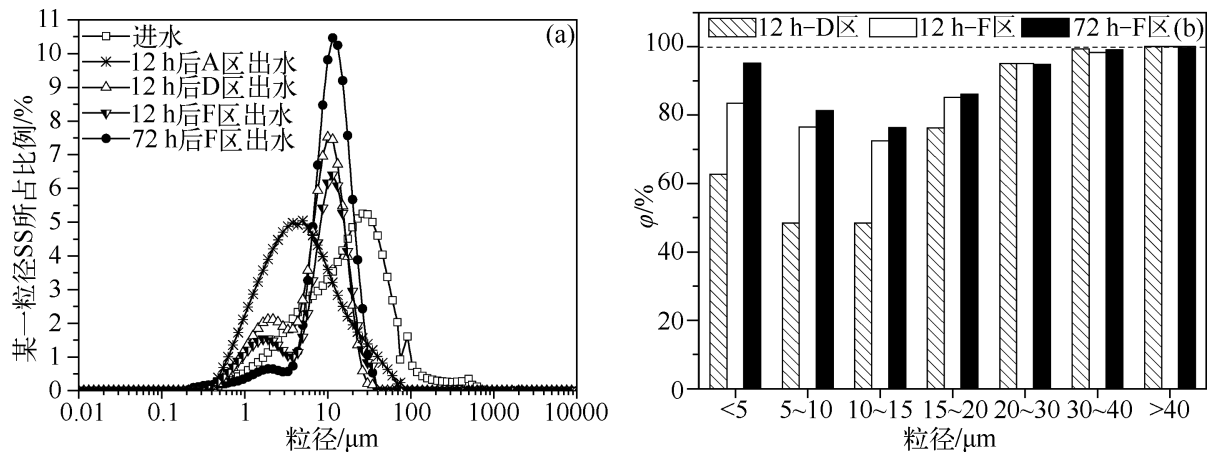

图 3 复合型前置库对 SS 去除前后粒径分布 (a) 及对不同粒径段累积去除率( b)

Fig. 3 SS partical size distribution of inflow and outflow (a) and the removal of different particle sizes (b) in pre-dam

复合型前置库系统能有效地去除粒径大于 $20 \mu \mathrm{m}$ 的颗粒, 平均去除率可达 $97 \%$ 以上. 而对于小于 $20 \mu \mathrm{m}$ 的颗粒受滞水时间、功能区的影响较大, 特别是小于 $10 \mu \mathrm{m}$ 的颗粒. 相比传统型前置库系统, $\mathrm{E}$ 和 $\mathrm{F}$ 
区的增加, 能显著提高小于 $15 \mu \mathrm{m}$ 粒径段的净化效果,可提高 $24 \%$ 左右. 而滞水时间对复合型前置库系统 而言, 作用并不明显, 多经过 $60 \mathrm{~h}$ 的处理, 粒径小于 $15 \mu \mathrm{m}$ 的颗粒仅提高 $6.8 \%$ 的去除率, 意味着从 SS 去 除角度,复合型前置库系统可大幅度缩短所需的滞水时间, 提高系统的处理效率. 同时, 也反映出小粒径

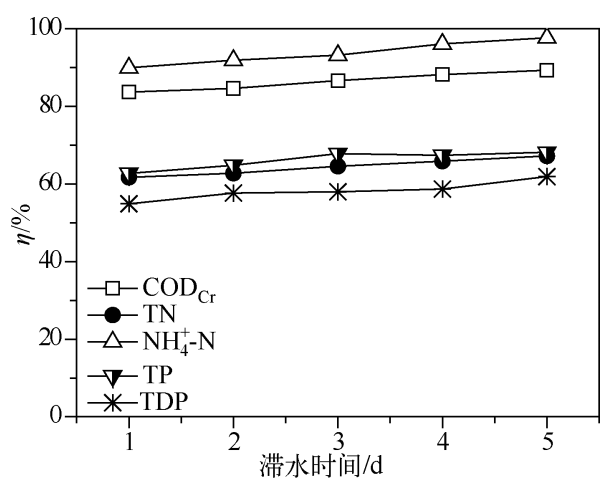

图 4 不同滞水时间下复合型前置库对 营养盐总体去除率

Fig. 4 Removal efficiency of nutrients with different retention time in pre-dam
颗粒在前置库系统中难以净化, 特别是粒径段为 5 $20 \mu \mathrm{m}$ 的颗粒. 因此, 若要进一步提升复合型前置库系统对 $\mathrm{SS}$ 的净化效果, 必须提高对 $5 \sim 20 \mu \mathrm{m}$ 颗粒的去除率 (图 $3 b)$.

\section{2 室内复合型前置库系统对营养盐的净化效果}

即使在冬季低温的条件下,复合型前置库对氮、磷等营 养盐仍具有良好的净化效果, $\mathrm{COD}_{\mathrm{Cr}} 、 \mathrm{TN} 、 \mathrm{TP}$ 的最高去除率 分别为 $89.3 \% 、 67.2 \% 、 68.2 \%$, 且随着滞水时间的增加而 增加, 但增幅较为平缓. 对于氮形态中的铵态氮, 其极易被 复合型前置库去除, 总体去除率可高达 $97.7 \%$; 而对于 TDP, 与 TP 净化呈现相似的规律, 意味系统中这部分的非溶 解态磷 (TP 与 TDP 差值) 并未随 SS 的沉降而被去除 (图 4).

氮、磷等营养盐累积去除率随水流沿程的增加而增加. 引人 $\mathrm{E}$ 和 $\mathrm{F}$ 区后, 明显提高了营养盐的去除率, $\mathrm{COD}_{\mathrm{Cr}} 、 \mathrm{TN}$ 、 $\mathrm{NH}_{4}^{+}-\mathrm{N} 、 \mathrm{TP}$ 去除率可分别提高 $5.82 \% 、 6.52 \% 、 6.34 \%$ 、 9.29\%(图 5a).

A 区对营养盐的去除起主要作用,对不同营养盐去除贡献率介于 $48.0 \% \sim 67.2 \%$ 之间,这与 SS 在该区 的去除率相接近, 意味着进水后营养盐可能随着 SS 的沉降而被去除. 其次是 B 区, 对不同营养盐去除的贡 献率接近 $20 \%$, 其中对 TP 去除的贡献达 $20.9 \%$. 除 A 与 B 区外, D 与 E 区在氮、磷的净化过程也起到了重 要的作用,两者的贡献率之和可占 $20 \%$ 左右, 体现出湿地系统及高种植密度深水区对氮、磷净化去除的重要 作用. 而对于 $\mathrm{C}$ 与 $\mathrm{F}$ 区, 对营养盐的贡献作用较低, 两者贡献率平均不及 $7 \%$; 其中 $\mathrm{C}$ 区在 $\mathrm{COD}_{\mathrm{Cr}} 、 \mathrm{NH}_{4}^{+}-\mathrm{N}$ 上明 显体现不足, 贡献率不及 $2.5 \%$. 另外, 相比较传统型的前置库而言, 复合型前置库在营养盐去除上并无显著 提高, 特别是在 $\mathrm{COD}_{\mathrm{Cr}}$ 和 $\mathrm{NH}_{4}^{+}-\mathrm{N}$ 去除上, 这可能受到温度等条件的影响 (图 5b). 此外, 只从贡献率角度不足 以反映出功能区实际效果, 考虑到各功能区的面积不同,引人单位面积贡献率的概念.
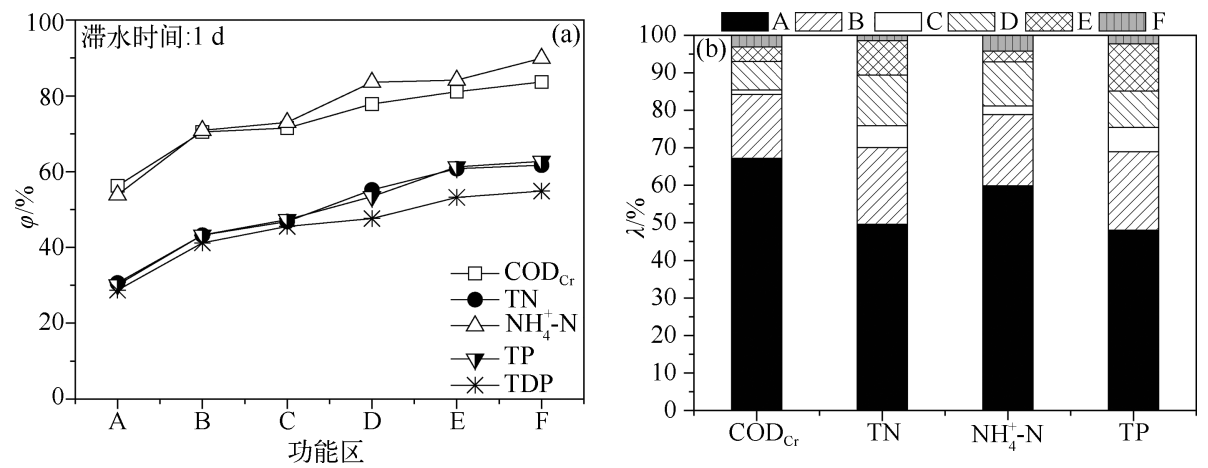

图 5 滞水时间 $1 \mathrm{~d}$ 条件下复合型前置库各功能区的累积去除率 (a) 及贡献率 (b)

Fig. 5 The cumulative removal efficiency (a) and contribution (b) to nutrients in different functional areas with retention time of 1 day

从表 1 可明确地看出 $\mathrm{A} 、 \mathrm{~B}$ 与 $\mathrm{E}$ 区的重要作用,其中 $\mathrm{E}$ 区在氮、磷的去除上体现出了高效性,在 $\mathrm{TP}$ 方面 高于 $\mathrm{A}$ 区, $\mathrm{TN}$ 方面与 $\mathrm{A}$ 区接近. $\mathrm{C}$ 和 $\mathrm{F}$ 区则分别在 $\mathrm{COD}_{\mathrm{Cr}} \mathrm{TN}$ 上体现了明显的缺陷, 这可能与进人该功能区 营养盐浓度及形态有关. 总体而言, 复合型前置库对营养盐具有良好的净化效果. 
表 1 不同功能区对营养盐的单位面积贡献率 $\left(\% / \mathrm{m}^{2}\right)$

Tab. 1 The $\varepsilon$ value of nutrients with different functional areas

\begin{tabular}{crrrr}
\hline 功能区 & $\varepsilon\left(\mathrm{COD}_{\mathrm{Cr}}\right)$ & $\varepsilon(\mathrm{TN})$ & $\varepsilon\left(\mathrm{NH}_{4}^{+}-\mathrm{N}\right)$ & $\varepsilon(\mathrm{TP})$ \\
\hline $\mathrm{A}$ & 156.76 & 115.67 & 139.62 & 111.97 \\
$\mathrm{~B}$ & 78.59 & 94.61 & 87.71 & 96.99 \\
$\mathrm{C}$ & 5.74 & 27.01 & 10.81 & 30.14 \\
$\mathrm{D}$ & 35.53 & 63.47 & 55.14 & 45.43 \\
$\mathrm{E}$ & 43.97 & 103.01 & 32.38 & 142.04 \\
$\mathrm{~F}$ & 11.51 & 5.54 & 15.71 & 8.58 \\
\hline
\end{tabular}

\section{3 讨论}

\section{1 滞水时间的影响}

滞水时间 (或停留时间) 是水处理系统中的重要参数, 在前置库系统中亦是如此, 特别是对以去除 SS 和 $\mathrm{TP}$ 为目的设计的前置库系统 ${ }^{[19-20]}$, 其颗粒磷、SS 的沉降需要较长时间. 但是在本文中滞水时间仅为 $12 \mathrm{~h}$ 就 能对 SS 起到良好的去除效果, 营养盐方面亦是如此, 滞水 $1 \mathrm{~d}$ 条件下氮、磷、有机物便取得良好的效果, 这可 能有以下几方面的原因: 1) 前置库系统中原有的低污染的蓄水对高污染的来水起到一定的稀释缓冲作用; 2) SS 吸附作用;3) 潜流人工湿地 (E) 区及沉水植物作用. 其中, 稀释缓冲作用往往被研究者所忽略, 但在前 置库容量设计中均会考虑到, 人工湿地净化作用显而易见, 因此不在这里赘叙. 而对于 SS 吸附作用及沉水 植物的作用研究较多 ${ }^{[21-22]}$, 其中 SS 的沉降所携带的营养盐, 并未实质性地去除, 仍残留在 A 区, 受到微生物 的作用将会释放, 造成严重的内源污染. 因此, 工程措施方面需要对 A 区进行定期的清淤. 而沉水植物的吸 收作用不可忽视, 即使在冬季也能保持较高的净化作用, 对营养盐的平均贡献率为 $10 \%$ 左右 (图 $5 \mathrm{~b}$ ), 但受 种植密度影响较大. 因此需要保证较高的种植密度, 同时又需要种植耐寒植物. 上述几个原因使得前置库系 统滞水时间大大缩短, 可为 $1 \mathrm{~d}$. 考虑到其可靠性, 可在实际工程中选择较长的滞水时间, 可为 $2 \sim 3 \mathrm{~d}$, 以保证其 净化效果. 另外, 只从滞水时间因素设计角度考虑是不够充分的, 在实际工程中应多考虑溧阳塘马水库的实 际情况, 特别是最大水力负荷、库容及所需达到水质等因素, 以达到复合型前置库的最大功效及最优设计.

\section{2 各功能区的作用及对工程措施的建议}

通过各功能区对 SS、氮、磷、有机物的贡献率可以明显地发现, A、B、E 区对 SS 去除起到重要的作用, 而 $\mathrm{E}$ 区对有机物的净化效果上相对 $\mathrm{A}$ 和 $\mathrm{B}$ 区作用并不明显 (图 $2 \mathrm{~b}$, 图 5b), 这可能与进人 $\mathrm{E}$ 区的有机物浓度及 冬季条件有关. 湿地系统净化有机物能力常受到温度的影响, 低温条件使其系统活性大幅降低, 造成其低效 性. 而对于 $\mathrm{C}$ 和 $\mathrm{F}$ 区, 其并未在有机物、氮、磷、SS 净化方面起到重要贡献, 因此在工程应用中可适度降低这 两功能区所占的面积(或库积). 另外, 从单位面积贡献率上也可说明 $A 、 B 、 E$ 区的重要作用(图 $2 b$, 表 1), 因 此在实际工程应用中可适当增加这 3 个功能区的面积 (或库容), 增强其净化效果. 对于 $\mathrm{F}$ 区的增加, 本质上 是进一步增加对水中低氮、磷浓度时氮、磷去除率, 但室内试验的结果表明, 其提高幅度非常有限, 特别是在 氮、磷的净化上, 这可能受以下两方面的影响:1) 冬天温度低的影响,生物膜的活性较低;2) 进水水质考虑不 足, 并未涉及到有机氮、磷, 使得微生物对有机氮、磷的贡献被忽略. 但是在对铵态氮与有机物的净化上仍有 一定的效果, 因此, 有必要进一步研究进水中含有有机氮、磷及夏季时该功能区的功效. 另外, 对于 SS 中 $5 \sim$ $20 \mu \mathrm{m}$ 粒径颗粒的净化作用, 可以通过增加沉水植物的种植密度及湿地功能区的面积, 进一步降低流速增加 沉水植物及湿地填料截留作用.

\section{4 结论}

引人潜流人工湿地及强化净化区构成复合型前置库分区净化系统, 揭示系统对面源主要污染物的去除 效果,通过研究得出如下结论:

1) 复合型前置库去除氮、磷、 $\mathrm{COD}_{\mathrm{Cr}}$ 均具有良好效果,最高可达 $67.2 \% 、 68.2 \% 、 89.3 \%$,滞水时间为 $1 \mathrm{~d}$ 
时, SS 可达到最高去除率的 $92 \%$ 左右, $2 \sim 3 \mathrm{~d}$ 时, 各污染物去除率增加较少并趋于稳定, 建议在塘马水库水 质安全保障工程应用中设计滞水时间为 $2 \sim 3 \mathrm{~d}$, 保证稳定的净化效果.

2) 引人 $\mathrm{E}$ 和 $\mathrm{F}$ 后, 能有效地提高 $\mathrm{SS}$ 、氮、磷、 $\mathrm{COD}_{\mathrm{Cr}}$ 的去除效果, 分别提高 $12.5 \% 、 6.52 \% 、 9.29 \%$ 、 $5.82 \%$, 贡献主要来自 $\mathrm{E}$ 区, E 区在对小颗粒(粒径小于 $15 \mu \mathrm{m}$ ) 的去除方面起着关键作用.

3 ) 基于各功能区的单位贡献率, 建议在塘马水库水质净化工程中适当增大 $A 、 B 、 D$ 及 $E$ 区的面积,而适 当减小 $\mathrm{C}$ 和 $\mathrm{F}$ 区的面积, 以提高复合型前置库的净化效率及占地面积利用率.

\section{5 参考文献}

［1］李仰斌,张国华,谢崇宝. 我国农村饮用水源现状及相关保护对策建议. 中国农村水利水电,2007,11:1-4.

[2] 柴世伟,斐晓梅,张亚雷等. 农业面源污染及其控制技术研究. 水土保持学报,2006,20(6):192-195.

[3] 李 涁,吕锡武,宁 平等. 河口前置库技术在面源污染控制中的研究进展. 水处理技术,2008,34(9):1-6.

[ 4 ] Uhlmann D, Benndorf J. The use of primary reservoirs to control eutrophication caused by nutrient inflows from non-point sources: land use impact on lake and reservoir ecosystems proceedings of a regional work shop on MAB project 5. Warsaw Facultas Wien, 1980: 152-188.

[ 5 ] Nyholm N, Sorensen PE, Olrik K et al. Restoration of lake nakskov indrefjord denmark, using algal ponds to remove nutrients from inflowing river water. Prog Wat Technol, 1978, 10:881-892.

[ 6 ] Fiala L, Vassata P. Phosphorus reduction in a man-made lake by means of a small reservoir in the inflow. Arch Hydrobiol, $1982,94: 24-37$.

[ 7 ] 阎自申. 前置库在滇池流域运用研究. 云南环境科学, 1996,15(6) :33-35.

[8] 杨文龙, 杜 娟. 前置库在滇池非点源污染源控制中的研究. 云南环境科学, 1996,12(4):8-10.

[ 9 ] 张毅敏,张永春. 前置库技术在太湖流域面源污染控制中的应用探讨. 环境污染与防治,2003,12(6):342-344.

[10]田猛, 张永春. 用于控制太湖流域农村面源污染的透水坝技术试验研究. 环境科学学报, 2006, 26 (10): 1665-1670.

[11] 段 伟, 刘昌明, 黄炳涁. 官厅水库人库口复合湿地系统对人库水质的净化. 北京师范大学学报: 自然科学版, $2009, \mathbf{4 5}(5 / 6): 595-601$.

[12] 陆海明,邹 鹰,孙金华等. 南方农村饮用水水源地生态防控体系示范工程一以南京市东龙河小流域为例. 水利 水运工程学报, $2011,3: 54-59$.

[13] 朱铭捷,胡洪营,何 苗等. 河道滞留塘系统对污染河水中氮、磷的去除特性. 生态环境,2006,15(1):11-14.

[14] 田景宏,黄炳涁. 利用黑土洼沟净化官厅水库人库水水质研究. 水文,2008,28(3):61-64.

[15] Paul L. Nutrient elimination in pre-dams: results of long term studies. 4th International Conference on Reservoir Limnology and Water Quality. Ceske Budejovice: Czech Republic, 2002, August 12-16.

[16] 袁冬海, 席北斗, 王京刚等. 固定化微生物一水生生物强化系统在前置库示范工程中的应用. 环境科学研究, 2006, 19 (5) : $45-48$.

[17] 高阳俊, 曹 勇,陈小华等. 浮床技术在淀山湖千墩浦前置库区的应用. 中国环境科学学会学术年会论文集, 2010, 2591-2594.

[18] 国家环境保护总局《水和废水监测分析方法》编委会. 水和废水监测分析方法: 第 4 版. 北京: 中国环境科学出版 社,2002.

[19] Paul L, Schruter K, Labahn J. Phosphorus elimination by longitudinal subdivision of reservoirs and lakes. Water Science and Technology, 1998, 37(2):235-243.

[20] Salvia-Castellvi M, Dohet A, Vander P et al. Control of the eutrophication of the reservoir of Esch-sur-Sûre ( Luxembourg) : evaluation of the phosphorus removal by predams. Hydrobiologia, $2001, \mathbf{4 5 9}(1 / 2 / 3): 61-71$.

[21] 朱铭捷, 胡洪营, 何 苗等. 悬浮颗粒物在河道滞留塘系统中的沉降与沉积特性. 环境污染治理技术与设备, 2006, $7(12): 27-31$.

[22] 张邦喜, 李存雄, 夏品华等. 沉水植物水质净化研究及在前置库中的应用. 安徽农业科学, 2010, 38 (2): 11931-11932. 